\title{
Knowledge of occupational health hazards and practice of personal protective equipment among fabrication workers in Kathmandu district, Nepal
}

\author{
Shrestha $\mathbf{B}^{1}$, Manandhar $\mathbf{N}^{1}$, Joshi SK ${ }^{1}$ \\ ${ }^{1}$ Department of Community Medicine, Kathmandu Medical College, Sinamangal, Kathmandu, Nepal
}

\section{ABSTRACT}

Background: Fabrication work is one of the hazardous occupations in which workers are exposed to different occupational hazards and injuries. But the workers lack proper knowledge about protecting themselves from those hazards. This study was conducted, to assess knowledge about occupational health hazards among fabrication workers and to find out the practice of Personal Protective Equipment (PPE) in fabrication works.

Methods: A cross-sectional study was conducted among 394 fabricator workers of Kathmandu District by using a multi-stage sampling technique. Participants were interviewed with a pre-tested semi-structured questionnaire. Results: All the participants were male, and their age ranged from 19-60 years with the mean age of 32.3 years. $71.3 \%$ of participants had work-related health complains, among which arc eye $(85.76 \%)$ was the most common. Among them, $87.1 \%$ had at least used one PPE. There was a significant association between awareness about occupational hazards and work experience of fabrication workers $(p=0.001)$, and the practice of PPE with religion $(p<0.01)$.

Conclusion: This study found that fabrication workers were aware of occupational hazards and the use of PPE during the fabrication work. But the practice of PPE was not enough to protect them from the occupational hazards.

Key words: Burns, Fabrication workers, Occupational hazards, Personal Protective Equipment.

\section{Introduction}

$\mathrm{O}$ ccupational health and safety (OHS) is defined as a concept of protecting the employees from impending harmful effect in the workplaces by early identification of the risks and timely intervention to prevent fatal and non-fatal accidents to the workers and the surroundings. ${ }^{1,2} \mathrm{OHS}$ is a multidisciplinary approach aimed at improvement of the health and potential of the workers, to create an effective and conducive work environment for the safety of the workers and to develop and implement a rational set

DOI: https://doi.org/10.3126/ijosh.v10i2.33330

Date of submission: 01.10.2020

Date of acceptance: 29.11 .2020

\section{Corresponding Author}

Dr. Bibeka Shrestha

Department of Community Medicine,

Kathmandu Medical College,

Sinamangal, Kathmandu, Nepal

Tel: +977 9841212990

Email: shresthabibeka@gmail.com

ORCID ID: 0000-0003-0050-341X of policies for organizational development and better work ethics. OHS plays a vital role to overcome the health hazards.

An occupational hazard is a risk harming the health of the workers at the workplace either immediately or after prolonged exposure. There are various types of hazards such as Physical, Chemical, Biological, Psychological, Mechanical and Ergonomic hazards. ${ }^{1}$ Based on severity or duration, it can be classified into acute and chronic effects such as burn, fracture, foreign body in the eye, hearing loss, bronchitis, and back pain etc. ${ }^{3,4}$ Since fabrication workers are directly exposed to different accidental and non-accidental types of hazards, early diagnosis of hazards and regular use of control measures in a workplace is an appropriate preventive measure against fabrication related occupational hazards. ${ }^{5}$

\section{(c) (1) (9)}

This journal is licensed under a Creative Commons AttributionNon Commercial 4.0 International License. 
Personal Protective Equipment (PPE) is the equipment used to prevent serious workplace illness and injuries by limiting exposure to continuous contact with physical, chemical, radiological, electrical and mechanical hazards. Equipment used for protection during fabrication is different according to hazards and body parts it is protecting. ${ }^{6,7}$

According to International Labor Organization (ILO) in 2015, 2.3 million people die at work from injury or disease related to their occupation and 2 million of them die due to fatal work-related diseases whereas more than 313 million were non-fatal accidents per year. ${ }^{8}$ Only $15 \%$ of workers have access to an assessment of occupational health risk, health surveillance, training for safe working method and first aid. ${ }^{9}$

The concept of occupational health and safety is evolving in Nepal. The first Labor Act was promulgated in 1992 A.D. ${ }^{10}$ The new Labor Act was launched in 2017 A.D. ensuring the provision for the rights, facilities, and safety of workers in the enterprises with even a single person at work. ${ }^{11}$ Though fabrication work is a skillful occupation which is being carried out since ancient time ${ }^{12}$ majority of fabrication workers learn their job without any formal training and supervision, thus lack:

i. Proper knowledge about fabrication work

ii. Proper use of PPE

iii. Proper knowledge about health hazards.

The prevalence of occupational health effects seems to be $90.7 \%$ according to a study conducted in the eastern part of Nepal. ${ }^{12,13}$ Thus, this study aimed to assess knowledge about occupational health hazards and the practice of Personal Protective Equipment (PPE) among fabrication workers.

\section{Methods}

A cross-sectional analytic study was conducted from March 2018 to September 2018 in Grill and steel fabrication workers of Kathmandu District, Nepal. Since not much study has been done in this field, the prevalence rate of $50 \%$ was taken into consideration. The sample size was calculated using formula

$$
\begin{aligned}
\text { Sample size }(\mathrm{n})=\frac{\mathrm{z}^{2} \times \mathrm{xpq}}{\mathrm{d}^{2}} & =\frac{(1.96)^{2} \times 0.5 \times 0.5}{0.05^{2}} \\
& =384.16 \approx 385
\end{aligned}
$$

Where, $Z=1.96$, at confidence level of $95 \%$ $\mathrm{P}=$ Prevalence $=50 \%=0.5$ $q=(1-p)=(1-0.5)=0.5$

$d=$ margin of error of $5 \%$

Including $5 \%$ non-response rate we planned to interview 405 fabrication workers.

A multistage sampling technique was used during the study where primary data of fabrication workers was obtained from the office of the Federation of Grill and Steel Fabricators Nepal. According to the available information, there were two local area committees of fabrication workers in Kathmandu that is East and West with 9 and 5 Units respectively. Out of those Units, 5 from East and 3 from West were selected by using Simple Random Sampling. From those selected Units, 203 workshops were selected using Population proportional to size (PPS). Taking two fabrication workers from selected workshops required sample size was reached by using convenience sampling. Fabrication workers both male and female of age 18 years and above, who have been working for 6-8 hours a day for at least 6 months in this field were included in the study. Fabrication workers with a history of any preexisting comorbidity were excluded. Data collection was done by interview method using pretested structured questionnaires. Ethical clearance was obtained from the Institutional Review Committee (IRC) of Kathmandu Medical College. Before collecting data, all the participants were informed in detail about the study and written consent was taken. Confidentiality of the participants was maintained. The collected data were entered in MS Excel and exported to the Statistical Package for Social Sciences (SPSS) version 25 for analysis.

\section{Results}

Data were collected from a total of 394 fabrication workers who agreed to participate in the study. Twelve respondents denied participating in the study, so the response rate was $97 \%$ (394). All the respondents of the study were male with a mean age of 32.30 years and Standard Deviation of 9.58 years. Majority of the respondents belonged to 25-34 years age group. In total $86 \%$ were Hindu by religion, $81.7 \%$ Janajati by ethnicity and more than $50 \%$ of fabrication workers were educated up to the secondary level of education.

Almost one fourth $(24.6 \%)$ of respondents had work experience of fewer than 5 years whereas, $98.2 \%$ were trained for work through apprenticeship. Most of the respondents reported working for less than 8 hours 
a day. During the study, electric welding (99.7\%) was commonly praticed where most of them reported doing grinding, welding, cutting, painting, and hammering as a part of their job. But none were involved in chemical cleaning of metal.

Occupational health effect of fabrication work was divided into two sections that were physical injuries during fabrication and work-related health complains. In the first section, all of the respondents replied that they were injured during fabrication work within the last year. The most common type of injuries was cuts and burns which occurred during grinding and welding of metals. The majority of the fabrication workers reported that their eyes (99.2\%) and hands were the commonest parts affected by fabrication work. (Table 1)

In the second section, out of 394 fabrication workers, $281(71.3 \%)$ had health-related complains within the last one year of working. Arc eyes $(85.76 \%)$ were the most common injuries related to fabrication work followed by headache $(25.26 \%)$, cough $(24.91 \%)$, back pain $(24.55 \%)$ and Skin Irritation (20.28\%). (Table 2)

Among the total respondent, $54.44 \%$ reported that the health problems had affected their daily work activities. Half of the fabrication workers $(49.7 \%)$ had visited hospitals for the treatment and $43.7 \%$ had received the first aid at their workplace.

The study showed that all the respondents were aware of occupational hazards in fabrication work. Electricity $(100 \%)$ was the commonest hazard in fabrication work followed by sharp edge metal (98.5\%), flying sparks (93.1\%) and bright light (90.4\%). (Figure 1)

All the respondents had used at least one PPE for six different body parts (Head/Eye, Ears, Nose and mouth, Upper Limb, Lower Limb, Body/ Trunk). Among them, sunglasses $(99.7 \%)$ for eyes, cotton face mask
(94.9\%) for nose and mouth, insulated gloves (97.9\%) for upper limbs, and ordinary shoes (93.8\%) for lower limb protection were most commonly praticed as PPE. Similarly, few respondents had used PPE for the protection of their trunk and none of the respondents had used any of the PPE for the ear. (Table 3)

There was a significant difference between the work experience and awareness of occupational hazards among fabrication workers $(p=0.001)$. Higher the experience in fabrication work had better awareness about occupational hazards. But there was no significant difference in awareness about occupational hazards with the duration of work per day and training. (Table 4)

There was a significant difference between the practice of PPE with the religion of respondents $(p=0.01)$. But there was no significant difference in knowledge about PPE with age and education level of fabrication workers $(p>0.05)$. (Table 5)

Interestingly respondents who had good knowledge about PPE had nearly one hundred- and forty-times higher odds of having good practice of personal protective equipment [COR: 140.05 ; $95 \% \mathrm{Cl} 31.49-$ 624.79] and this association was found to be statistically significant $(p<0.001)$. (Table 6$)$

In multivariate analysis, the respondents who had worked for more than eight hours per day were found to have less practiced PPE (AOR: 0.39 ; $95 \% \mathrm{Cl} 0.17-$ 0.88 ) as compared to those who have worked less than eight hours per day which was found to be statistically significant $(p=0.02)$. Similarly, the respondent who had good knowledge about PPE had nearly one hundred fifty times higher odds of using PPE (AOR: 150.24; 95\% Cl: 29.76-758.46) which was also statistically significant since $p$-value was less than 0.001 .

Table 1: Distribution of injuries and body part affected within 1 year*

\begin{tabular}{lcc}
\hline Variables & Number of workers $(\mathbf{n})$ & Percentage (\%) \\
\hline No. of injuries per year & & 56.3 \\
$\leq 7$ & 222 & 43.7 \\
$>7$ & 172 & 99.5 \\
Injuries during fabrication* & & 3.8 \\
Cuts & 392 & 3 \\
Broken bones & 15 & 99.7 \\
Sprain & 12 & \\
Burns (spark injuries) & 393 &
\end{tabular}




\begin{tabular}{lcc}
\hline Variables & Number of workers (n) & Percentage (\%) \\
\hline Body parts affected * & & 99.2 \\
Eyes & 391 & 0.5 \\
Head & 2 & 0.3 \\
Neck & 1 & 92.6 \\
Hands & 365 & 75.1 \\
Legs & 296 & 0.8 \\
Back & 3 & 96.4 \\
Work during injury* & & 90.1 \\
Grinding & 380 & 13.2 \\
Welding & 355 & 1.3 \\
Hammering & 52 & \\
Cutting & 5 & \\
\hline
\end{tabular}

*Multiple responses

Table 2: Distribution of work-related health complains* $(n=281)$

\begin{tabular}{lcc}
\hline Parameter & Frequency(n) & Percentage (\%) \\
\hline Health Complains & & 85.76 \\
Arc eyes & 241 & 25.26 \\
Headache & 71 & 24.91 \\
Cough & 70 & 24.55 \\
Back Pain & 69 & 20.28 \\
Skin Irritation & 57 & 4.62 \\
Breathing Problem & 13 & 0.35 \\
\hline Hearing Impairment & 1 & \\
\hline
\end{tabular}

*Multiple Responses

Table: 3 Distributions of PPE practiced among the respondents *

\begin{tabular}{|c|c|c|c|}
\hline Body Parts & Variables & Frequencies (n) & Percentage (\%) \\
\hline \multirow{4}{*}{ Head /Eye } & Safety glass & 2 & 0.5 \\
\hline & Hand shield & 26 & 6.6 \\
\hline & Welding helmet & 21 & 5.3 \\
\hline & Sunglass & 393 & 99.7 \\
\hline \multirow{2}{*}{ Ear } & Ear plug & 0 & 0 \\
\hline & Cotton & 0 & 0 \\
\hline \multirow{2}{*}{ Nose and mouth } & Face mask & 351 & 94.9 \\
\hline & Respirator & 0 & 0 \\
\hline \multirow{3}{*}{ Upper Limbs } & Insulated gloves & 380 & 97.9 \\
\hline & Surgical gloves & 0 & 0 \\
\hline & Woolen gloves & 20 & 5.15 \\
\hline \multirow{3}{*}{ Lower limbs } & Safety boots & 16 & 4.1 \\
\hline & Ordinary shoes & 365 & 93.8 \\
\hline & Slipper & 47 & 12.1 \\
\hline \multirow{2}{*}{ Body /Trunk } & Work suit & 2 & 1.3 \\
\hline & Jeans apron & 4 & 2.5 \\
\hline
\end{tabular}

*Multiple Responses 
Table 4: Factor associated with awareness about occupational health hazards among fabrication workers

\begin{tabular}{|c|c|c|c|c|}
\hline & Awareness abc & upational he & & \\
\hline Variables & & & COR $(95 \% \mathrm{Cl})$ & p-value \\
\hline & Good & Poor & & \\
\hline Work Experience & & & & \\
\hline$<61$ & $49(50.5 \%)$ & $48(49.5 \%)$ & $0.68(0.37-1.23)$ & \\
\hline $61-120$ & $32(42.7 \%)$ & $43(57.3 \%)$ & $0.49(0.26-0.94)$ & \\
\hline $121-180$ & $45(60.8 \%)$ & $29(39.2 \%)$ & $1.03(0.54-1.97)$ & 0.001 \\
\hline $181-240$ & $21(30.9 \%)$ & $47(69.1 \%)$ & $0.29(0.15-0.58)$ & \\
\hline$>240$ & $48(60 \%)$ & $32(40 \%)$ & $\mathrm{RC}$ & \\
\hline Duration of work & & & & \\
\hline$\leq 8$ & $141(50.4 \%)$ & $139(49.6 \%)$ & $1.13(0.73-1.74)$ & 0 \\
\hline$>8$ & $54(47.4 \%)$ & $60(52.6 \%)$ & $\mathrm{RC}$ & (.) \\
\hline Training & & & & \\
\hline Apprenticeship & $190(49.1 \%)$ & $197(50.9 \%)$ & $0.39(0.074-2.31)$ & 0 \\
\hline Certified institute & $5(71.4 \%)$ & $2(28.6 \%)$ & $\mathrm{RC}$ & 0.24 \\
\hline
\end{tabular}

COR: Crude odds ratio, RC- Reference Category, Cl-Confidence Interval

Table 5: Factors associated with the practice of Personal Protective equipment

\begin{tabular}{|c|c|c|c|c|c|}
\hline \multirow[t]{2}{*}{ Characters } & \multicolumn{2}{|c|}{$\begin{array}{l}\text { The practice of Personal } \\
\text { Protective Equipment's }\end{array}$} & \multirow[t]{2}{*}{ COR $(95 \% \mathrm{CI})$} & \multirow[t]{2}{*}{ AOR $(95 \% \mathrm{Cl})$} & \multirow[t]{2}{*}{ p-value } \\
\hline & Good & Poor & & & \\
\hline \multicolumn{6}{|l|}{ Age in years } \\
\hline$<25$ & $91(82.7 \%)$ & 19(17.3\%) & $\mathrm{RC}$ & $\mathrm{RC}$ & \\
\hline $25-34$ & $109(90.8 \%)$ & $11(9.2 \%)$ & $2.06(0.93-4.57)$ & $1.59(0.59-4.29)$ & \\
\hline $35-44$ & $105(89.7 \%)$ & $12(10.3 \%)$ & $1.82(0.84-3.96)$ & $1.98(0.68-5.73)$ & 0.09 \\
\hline $45-54$ & $32(78 \%)$ & $9(22 \%)$ & $0.74(0.30-1.80)$ & $0.55(0.16-1.92)$ & \\
\hline$\geq 55$ & $6(100 \%)$ & - & - & & \\
\hline \multicolumn{6}{|l|}{ Education level } \\
\hline Illiterate & $2(66.7 \%)$ & $1(33.3 \%)$ & $\mathrm{RC}$ & $\mathrm{RC}$ & 0.14 \\
\hline Informal education & $11(91.7 \%)$ & $1(8.3 \%)$ & $5.50(0.23-128.96)$ & $3.31(0.01-672.16)$ & \\
\hline Primary school & $83(81.4 \%)$ & $19(18.6 \%)$ & $2.18(0.18-25.35)$ & $0.31(0.003-32.28)$ & \\
\hline Secondary school & $183(87.6 \%)$ & $26(12.4 \%)$ & $3.51(0.30-40.18)$ & $0.46(0.005-47.50)$ & \\
\hline Higher secondary school & $60(95.2 \%)$ & $3(4.8 \%)$ & $10.00(0.69-143.8)$ & $1.17(0.01-142.03)$ & \\
\hline Bachelor or more & $4(80 \%)$ & $1(29 \%)$ & $2.00(0.07-51.59)$ & $0.20(0.001-34.08)$ & \\
\hline \multicolumn{6}{|l|}{ Religion } \\
\hline Hindu & $300(88.5 \%)$ & $39(11.5 \%)$ & $\mathrm{RC}$ & $\mathrm{RC}$ & \\
\hline Buddhist & $10(58.8 \%)$ & $7(41.2 \%)$ & $0.91(0.19-4.15)$ & $0.30(0.06-1.47)$ & \\
\hline Muslim & $14(87.5 \%)$ & $2(12.5 \%)$ & $0.18(0.06-0.51)$ & $0.52(0.10-2.55)$ & 0.01 \\
\hline Christian & $14(87.5 \%)$ & $2(12.5 \%)$ & $0.91(0.19-4.15)$ & $0.58(0.08-4.24)$ & \\
\hline Others & $5(83.3 \%)$ & $1(16.7 \%)$ & $0.65(0.07-5.70)$ & $0.58(0.06-5.41)$ & \\
\hline
\end{tabular}

AOR: Adjusted Odds Ratio, COR: Crude odds ratio, RC- Reference Category, Cl -Confidence Interval

Table 6: Knowledge and practice of Personal Protective equipment of the respondents

\begin{tabular}{|c|c|c|c|c|c|}
\hline \multirow{2}{*}{ Knowledge } & \multicolumn{2}{|c|}{ Practice } & \multirow{2}{*}{ COR $(95 \% \mathrm{CI})$} & \multirow{2}{*}{ AOR $(95 \% \mathrm{Cl})$} & \multirow{2}{*}{ p-value } \\
\hline & Good & Poor & & & \\
\hline Poor & $28(54.9 \%)$ & $23(45.1 \%)$ & $\mathrm{RC}$ & $\mathrm{RC}$ & \multirow{2}{*}{$<0.001$} \\
\hline Good & $341(99.4 \%)$ & $2(0.6 \%)$ & $140.05(31.49-624.79)$ & $150.24(29.76-758.46)$ & \\
\hline
\end{tabular}

AOR: Adjusted Odds Ratio, COR: Crude odds ratio, RC- Reference Category, Cl -Confidence Interval 


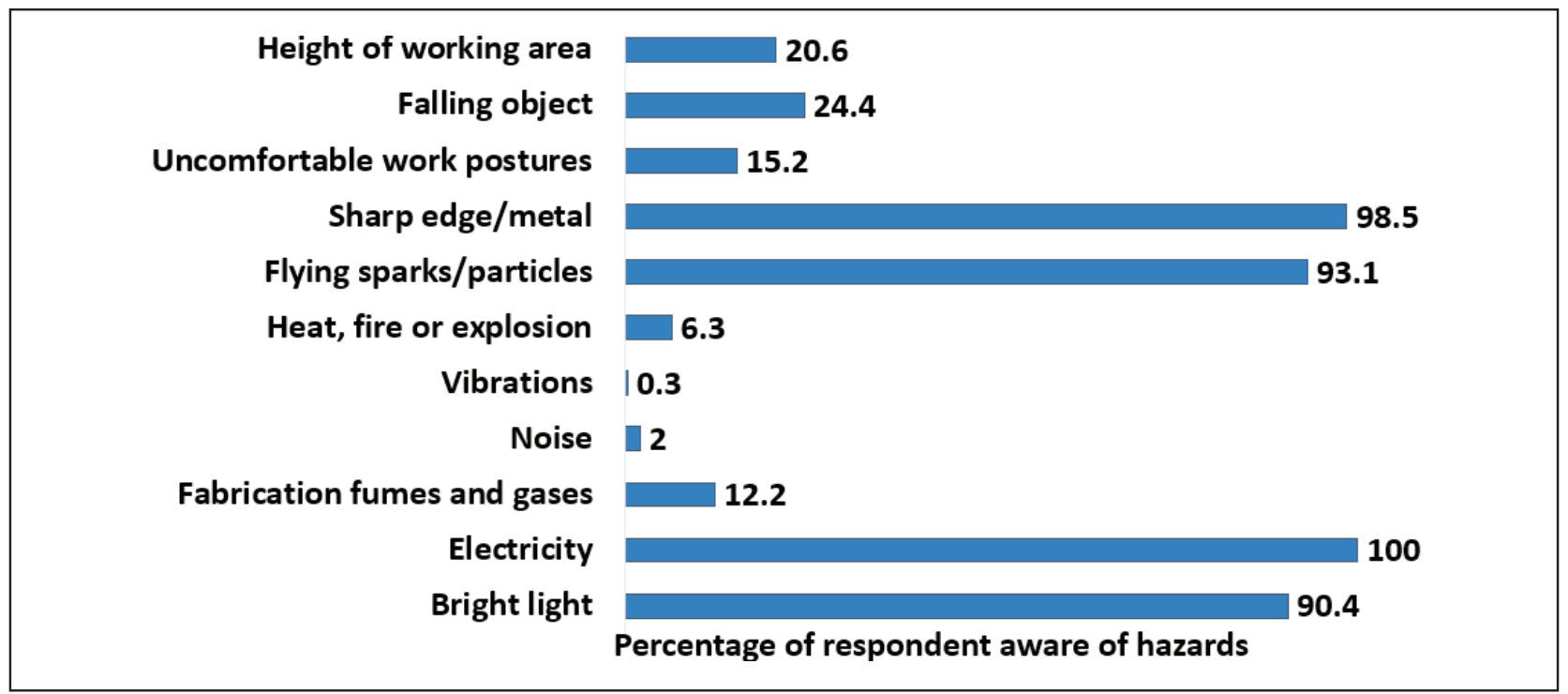

Figure 1: Awareness about the hazards of fabrication work (Multiple responses)

\section{Discussion}

This study revealed that all the respondents were males. Females do not prefer this field of profession due to demanding physical workload and hazardous working environments. Likewise, there are few other studies done in Nepal, India, Pakistan, and Ethiopia that showed similar kind of gender bias in this occupation. ${ }^{12,14-16}$ Due to this disparity the government needs to implement occupational health and safety strictly to generate employment for females in this field.

The majority of the respondents were aged between 25 and 34 years which is similar to a study conducted in Vellore of Southern India. ${ }^{17}$ That may be due to the similar employment opportunity of the countries. Although, the majority of respondents were literate only half of them had schooling up to the secondary level (Grade 6-10) which explains the reason why most of them had poor working environment and less use of PPE. This matches a similar study done in Pakistan that had highlighted that the majority of workers were educated up to the primary level of education. ${ }^{15}$ Thus with the similarity of these studies and the workers having limited education in this field of fabrication.

In the present study, the majority of respondents had work experience of fewer than five years and learned their work under the guidance of other experience fabrication worker i.e. apprenticeships. The result is similar to other studies conducted in eastern Nepal $(100 \%)$, India (87.7\%), Pakistan (91.4\%) and Nigeria $(91.5 \%){ }^{12,14,15,18}$ This may be to save the cost of vocational training and earn some money during the apprenticeship and likely due to the poor financial condition of the fabrication workers. The higher turnover rate in this field of work could be due to lesser payment in other fields of work for similar education level. The fact that capital investment to start a low scale fabrication workshop is low and those who had moved out to the city in search of work on limited educational background, fabrication becomes a good option. Therefore, fabrication workers who were not trained regarding the use of safety measures and impending hazards at the workplace are at a higher risk of suffering from its hazards.

All the respondents in this study were found to have been injured in the last one year during fabrication works and the most common injury was burn (99.7\%) followed by the cut injuries (99.5\%). This is in contrast to the result in South coast India where abrasions and lacerations were most common and about half of the respondents had burn injuries. ${ }^{19}$ This difference may be due to the workers do not take burns as a part of the work hazard and rarely use any preventive measures. They are negligent on the burn injury itself.

Out of the total fabrication workers, all of them had one or multiple complains and the commonest was arc eye $(85.76 \%)$. Arc eyes are painful inflammation of the cornea due to flash burn resulting in watery eyes, blurred vision and gritty sensation in the eye. ${ }^{20}$ This result is similar to the studies conducted in Benin city of Nigerian where $75.7 \%$ of workers had arc eye, in Ethiopia (99.6\%) and in south coastal India where the workers had $82.8 \%$ of flash burns. ${ }^{19,21,22}$ 
However, the study conducted in eastern Nepal showed a higher percentage of skin problems. ${ }^{13}$ This variation in injuries may be due to the method of welding adopted there and depends on the use of protective measures by fabrication workers.

Amongst the potential hazards, electricity (100\%) was the commonest hazard followed by sharp edge metal (98.5\%), flying sparks (93.1\%) and bright light $(90.1 \%)$. But around one-fifth respondents considered noise, fabrication fumes and gases as potential hazards. These findings were similar to study from Ethiopia. ${ }^{16}$

However, a study from eastern Nepal revealed that bright light was the most frequent hazard encountered followed by welding fumes and gases. In another study conducted in Zambia revealed ergonomic hazards like lifting metals as the commonest hazard. ${ }^{12,23}$ This variation regarding awareness of hazards is likely due to the different experiences of the fabrication workers and lack of knowledge on occupational health and their probable hazards.

Fabrication hazards like noise and vibration though irritating, health effects in exposed persons, are seen only after a long duration of exposure which might be the reason why the workers consider these potential causes as less hazardous by the workers.

On the contrary to this study, studies in Northern Nigeria and the Benin City of Nigeria showed $60.9 \%$ and $35.9 \%$ of workers respectively were found using safety goggles. ${ }^{18,22}$ This difference of use of PPE may be due to the availability of protective gear and the knowledge about PPE in Nigerian fabrication workers than in Nepal. In Nepal, the use of sunglasses instead of safety goggles is probably because these are cheaper, easily available and are provided by the employer to their employees and the majority of them consider it as a protective gear. Some of the fabrication workers avoid the use of goggles due to poor visibility in the work stations and discomfort while using them.

In this study out of total respondents, $97.9 \%$ practiced the use of insulated gloves. The workers who use gloves daily was only $12.3 \%$. The use of gloves was less because of discomfort on performing work by using insulated gloves and the use was higher in winter due to the need to touch cold metals.

Fabrication workers who had informal education had an $82 \%$ chance of having less awareness about occupational hazards as compared to those who were educated up to bachelor or more. But the relationship is found to be not statistically significant $(p=0.34)$. In contrast to this, the study conducted in Northern Nigeria showed the level of education was significant with occupational hazards. ${ }^{24}$ Similarly, the increase in education level was found to be significantly associated with awareness about occupational hazards in Lideta Sub-city, Addis Ababa, Ethiopia and eastern part of Nepal. ${ }^{12.21}$

In the present study, regarding occupational information of respondents, those who had better work experience were found to be more aware of occupational hazards compared to those with lesser work experience in fabrication work and the relationship is statistically significant ( $p=0.001)$. Similarly, a cross-sectional study from eastern Nepal revealed that the work experience was associated with awareness about occupational hazards. ${ }^{12}$ Other studies conducted in Ethiopia and Northern Nigeria also showed a similar result. ${ }^{18,21}$

The education level of respondents was not associated with practice about PPE. On the contrary, another study conducted in Ethiopia showed an association of education level with practice about PPE. It revealed that fabrication workers with certificate level education had 13 times more chance having good practice about PPE. ${ }^{16}$

In the current study, religion and practice about PPE depict that in comparison to Hindus, Buddhist and Christian fabrication workers had less practice about PPE and is statistically significant $(p=0.01)$. Though there is not any study that showed a relationship of practice about PPE with Religion, the use of PPE is higher in Hindu religion fabrication workers. The likely rationale being that the study conducted in the region had most Hindu respondents.

\section{Conclusion $\square$}

About $86 \%$ of the respondents have occupational health effects within one year. All of the respondents were found to know about occupational hazards. Regarding PPE, $84 \%$ of fabrication workers practice PPE for at least one part of the body among six parts of the body during their work.

Although most fabrication workers were aware of the occupational hazards and PPE from experience, this has not been reciprocated in practice about PPE. 


\section{Recommendation}

Fabrication workers must have the institutional training and the facility licensing to strengthen knowledge regarding occupational health hazards and proper use of modern PPE. The employers must maintain a healthy occupational environment, provide suitable and comfortable PPE and make sure all the employees use them.

The government should enforce proper working guidelines including the minimum payment and PPE at the workplace. The government must assign a Labour Inspector who time to time inspects and report the status of the workplace, injuries, and accidents due to the occupation. The government must enlist all the unregistered workshops so that the proper database can be made for monitoring, implementing safety rules and cross-check institutes.

\section{References}

1. Bhagawati B. Basics of occupational safety and health. IOSR JESTFT[Internet]. 2015 Aug [cited 2019 Dec 24];9(8):91-4. Available from:https:// www.iosrjournals.org/iosr-jestft/papers/vol9-issue8/ Version-1/N09819194

2. Ministry of social welfare and youth. Occupational Safety and health policy Document 2016-2020, On the road to a safer and healthier culture at work. Albania:2016 March. Available from: http://www.ilo. org/dyn/legosh/en/f?p=14100:503:164399800729::N O:503:P503_REFERENCE_FILE_ID:316079:NO

3. Occupational safety and health administration. Health hazards definition [Internet]. Occupational safety and health administration; [cited 2019 Nov 18]. Available from: https://www.osha.gov/laws-regs/regulations/ standardnumber/1917/1917.28AppA

4. International labor Organization. International hazard datasheet on occupation [Internet]. International labor Organization; [updated 2000 Nov 15; cited 2019 Nov 14] Available from: https://www.ilo.org/wcmsp5/ groups/public/---ed_protect/---protrav/---safework/ documents/publication/wcms_190162.pdf

5. International labor Organization. International hazard datasheet on occupation [Internet]. International labor Organization; [updated 2000 Nov 15; cited 2019 Nov 14] Available from: https://www.ilo.org/wcmsp5/ groups/public/---ed_protect/---protrav/---safework/ documents/publication/wcms_190162.pdf

\section{Limitation}

The study analyzes a limited sample of workers from a large urban area. So, a larger sample with geographical diversity is better to generalize the results. The result of the study is based on self-reporting regarding past one year injuries may present the recall bias. The study failed to explore the availability of PPE while performing their work

\section{Acknowledgements}

We would like to thank all the fabrication workers who participated in the study for their valuable time. The authors are also thankful to Grill and Steel Federation for providing the list of workshops in each Ekai.

\section{Funding}

University Grant Commission, Sanothimi, Bhaktapur has provided with financial support for this research by awarding with "The University Grant Commission Masters Research Support 2075-2076".

6. Alli BO. Fundamental principles of occupational health and safety. 2nd ed. Geneva: International Labor Organization;2008

7. Healthy working lives. Personal Protective Equipment (PPE)[Internet]. Healthy working lives [updated 2019 may 07; 2019 Dec 1] Available from: https://www. healthyworkinglives.scot/workplace-guidance/safety/ personal-protective-equipment/Pages/types-of-ppe. aspx

8. International Labor Organization. Global trends on occupational accidents and diseases [internet]. International Labor Organization; 2015 April 28 [cited 2018 Nov 12]. Available from: https://www.lo.org/ legacy/english/osh/en/story_content/external_files/ fs_st_1-ILO_5_en.

9. World Health Organization. International consultation on worker's health coverage [Internet]. Semnan, Islamic Republic of Iran: World Health Organization; 2014 April 28-30 [cited 2018 Nov 18]. Available from: https://www.who.int/mediacentre/events/ meetings/2014/workers-health/en/

10. Labour Act 2048(1992). Nepal Gazette: Government of Nepal. 44p Available from: http://www. lawcommission.gov.np/en/archives/16878

11. Upreti AR, Chaulagain N, Pandey TB. Labor Act 2017 (2074) - Major Highlight [internet]. Pioneer law association; 2017 Sep 7 [cited 2019 Nov 15]. Available from: http://www.pioneerlaw.com/news/ labor-act-2017-2074-major-highlights 
12. Budhathoki SS, Singh SB, Sagtani RA, Niraula SR, Pokharel PK. Awareness of Occupational Hazards and use of Safety Measures among Welders: A Cross-sectional Study from Eastern Nepal. BMJ Open [Internet]. 2014 May [cited date 2017 Sep 24 ]; 4:1-6. Available from: http://bmjopen.bmj.com/cgi/ doi/10.1136/bmjopen-2013-004646

13. Budhathoki SS, Singh SB, Niraula SR, Pokharel PK. Morbidity Patterns among the Welders of Eastern Nepal: A Cross-sectional Study. AOEMJ [Internet]. 2016 Nov 15 [Cited date 2017 Sep 24]; 28(1):6268 Available from:https://aoemj.biomedcentral.com/ articles/10.1186/s40557-016-0151-y

14. Joseph N, Venkatesh V, Akash S, Hegde S, Moras E, Shenoy NP. Occupation Hazards - Pattern, Awareness and Preventive Measures among Welders from an Unorganized Sector in India. JCDR[Internet]. 2017 May [cited 2019 Jun 22]; 11(5):LC23-8. Available from: https://www.ncbi.nlm.nih.gov/pmc/ articles/PMC5483716/

15. Hassan SM, Nasir U, Anwar K, Talib U. An assessment of the level of awareness and reported complaints regarding occupational health hazards and the utilization of personal protective equipments among the welders of Lahore, Pakistan. Int J Occup Env Heal [Internet]. 2017 [cited 2019 oct 20]; 23(2):98109. Available from: https://www.tandfonline.com/doi/ abs/10.1080/10773525.2018.1426259

16. BeyeneGebrezgiabher $B$, Tetemke D, Yetum $T$. Awareness of Occupational Hazards and Utilization of Safety Measures among Welders in Aksum and Adwa Towns, Tigray Region, Ethiopia, 2013. Jeph [Internet]. 2019 Jan 21 [cited 2019 Dec 5]; 2019:1-7. Available from: https://www.hindawi.com/journals/ jeph/2019/4174085/abs/

17. Alexander V, Sindhu KN, Zechariah $P$,et al. Occupational Safety Measures and Morbidity among Welders in Vellore, Southern India. Int J Occup Env Heal [Internet]. 2016 Sep 28 [cited 2019 Nov 20];
22(4):300-6. Available from: https://www.tandfonline. com/doi/abs/10.1080/10773525.2016.1228287

18. Sabitu K, lliyasu Z, Dauda MM. Awareness of occupational hazards and utilization of safety measures among welders in kaduna metropolis, Northern Nigeria. Ann Afr Med [Internet]. 2009 Jan 1 [cited 2019 Dec 6]; 8(1):46. Available from: http:// www.annalsafrmed.org/article.asp?issn=1596-3519;

19. Kumar S, Dharanipriya A. Prevalence and pattern of occupational injuries at workplace among welders in coastal south India. IJOEM [Internet]. 2014 Dec [cited 2019 Dec 10]; 18(3):135-9. Available from: https:// www.ncbi.nlm.nih.gov/pmc/articles/PMC4292199/

20. Industrial safety and hygiene news. All about welder's flash or arc eye [Internet]. Industrial safety and hygiene news; 2019 Apr 19[cited 2019 Dec 21]. Available from: https://www.ishn.com/articles/103728-allabout-welders-flash-or-arc-eye

21. Tadesse S, Bezabih K, Destaw B, Assefa Y. Awareness of occupational hazards and associated factors among welders in Lideta Sub-City, Addis Ababa, Ethiopia. J Occup Med Toxicol [Internet]. 2016 Apr 5 [cited 2019 Dec 10]; 11(1) 1-6. Available from: https://occup-med.biomedcentral.com/ articles/10.1186/s12995-016-0105-x

22. Isah, E.C., O.H. Okojie. Occupational Health Problems of Welders in Benin City, Nigeria. J Biomed Sci. [Internet] 2006 Jun [cited 2019 oct 11]; 5(1):6469. Available from: https://pdfs.semanticscholar.org/ ed46/15dff23961e166a2f0c

23. Siziya S, Rudatsikira E, MweembaA, et al. Exposure to occupational health hazards among Zambian workers. Occup Med [Internet]. 2013 Mar 1 [cited 2019 Dec12]; 63(2):109-15. Available from: https:// academic.oup.com/occmed/article/63/2/109/1375494

24. Canadian centre for Occupational Health and Safety [Internet]. Canadian centre for Occupational Health and Safety [updated 2017 Sep 18; cited 2019 Nov 17] Available from: https://www.ccohs.ca/oshanswers/ safety_haz/welding/ppe.htm 